\title{
A Case of Wheat-Dependent Exercise-Induced Anaphylaxis
}

\author{
Hee Bong Lee, M.D., In Su Ahn, M.D., Ji Hoon Choi, M.D., Chun Wook Park, M.D., \\ Cheol Heon Lee, M.D.
}

Department of Dermatology, College of Medicine, Hallym University, Seoul, Korea

Foods are recognized as a common cause of urticaria; however, the role of food is considered to be more important in acute not chronic urticaria. Wheat is a basic ingredient found in many common foods. Food allergy to wheat is primarily described in children in the form of atopic dermatitis. It is rare in adults; where it is mainly reported in exercise-induced anaphylaxis. We report a case of wheat dependent exercise-induced anaphylaxis that occurred in a 54-year-old Korean woman. (Ann Dermatol 21(4) 447 449, 2009)

\section{-Keywords-}

Food allergy, Wheat dependent exercise induced anaphylaxis

\section{INTRODUCTION}

Wheat is one of the major ingredients of food common to the Korean diet; it can be responsible of food-induced allergic reactions. This is frequently observed in children, but rarely described in adults. Wheat allergies can induce different symptoms such as the atopic eczema/dermatitis syndrome (AEDS), urticaria, and wheat-dependent exercise-induced anaphylaxis (WDEIA) $)^{1-3}$. In addition to classic IgE-mediated allergic responses, food allergies can also be mediated by immune complexes, as well as delayed and/or activated Toll-like receptors.

We report a case of wheat-dependent exercise-induced

Received December 7, 2008, Revised May 6, 2009, Accepted for publication June 16, 2009

Reprint request to: Cheol Heon Lee, M.D., Department of Dermatology, Kangnam Sacred Heart Hospital, College of Medicine, Hallym University, 948-1, Daerim 1-dong, Yeongdeungpo-gu, Seoul 150-950, Korea. Tel: 82-2-829-5221, Fax: 82-2-832-3237, E-mail: dermlee@ yahoo.co.kr anaphylaxis in a 54-year-old woman.

\section{CASE REPORT}

A 54-year-old Korean woman presented to the outpatient clinic with a five-year history of wheat flour allergy. She was diagnosed with hypertension 20 years previously and hyperthyroidism 10 years prior to her visit. Minutes to hours after consuming products containing wheat such as noodles, bread, or other snacks, the patient developed itching, generalized urticaria, mild to moderate dyspnea and short-term loss of consciousness. The patient presented to the clinic to determine the exact cause of these problems and learn about possible treatment.

The laboratory studies showed that the MAST (multiple antigen simultaneous test) and CAP-RAST (wheat) tests were within normal limits. The skin prick test had a negative wheat response. We carried out a fasting oral challenge test using a wheat flour product (clear soup with wheat flakes cooked with synthetic flavoring and no salt) and after two hours of observation, there was no visible reaction.

The following week, we carried out an exercise test 20 minutes following wheat meal consumption. After this test, the patient developed itching, generalized erythematous wheals and mild dyspnea (Fig. 1). The symptoms were relieved by intravenous antihistamines, corticosteroids, and fluids. The following week we found that exercise alone produced no reaction. As a result of these tests a diagnosis of wheat-dependent exercise-induced anaphylaxis was made.

\section{DISCUSSION}

Foods are recognized as a common source of urticaria in patients; however, the role of food is considered to be 

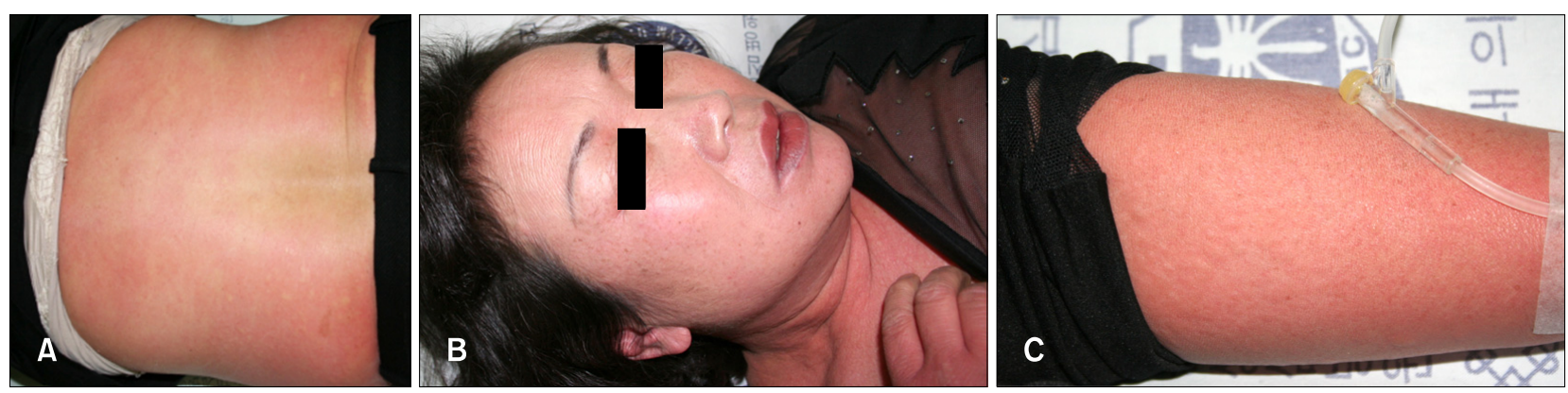

Fig. 1. (A) Twenty minutes after consumption of wheat meal products and subsequent walking, the patient developed itching, generalized erythematous wheals, and mild dyspnea. (B) Erythematous wheals on the face and neck. (C) Erythematous wheals on the arm.

more important in patients with acute urticaria than in patients with chronic urticaria ${ }^{4,5}$. Food allergies to wheat are primarily described in children in the form of atopic dermatitis, and are rarely observed in adults ${ }^{6}$.

Food allergies and food hypersensitivity involve the immune system ${ }^{7}$. Studies involving the characterization and isolation of food allergens suggest that the majority of offending agents are glycoproteins ${ }^{8}$. Reactions resulting from idiosyncratic, metabolic, toxic, or pharmacologic responses to food substances are referred to collectively as food intolerance ${ }^{9}$.

The diagnostic tools available to determine whether food plays a role in urticaria include the patient history, physical examination, skin and/or radioallergosorbent testing (RAST), diet and symptom diaries, elimination diets, and food challenges ${ }^{10}$. An oral provocation test is the most relevant method for determining the etiology of urticaria. The double-blind placebo-controlled food challenge currently remains the 'gold standard' for the diagnosis of a food allergy. This method has risks as it is occasionally followed by severe adverse reactions including anaphylaxis. Skin testing, such as the prick or scratch tests, is relatively safe compared to an oral challenge. However, these methods can be affected by medication such as anti-histamines and medications taken for allergies. In vitro specific IgE tests are can be performed safely without concern about the effects by medications; however, they occasionally show false positive or false negative results ${ }^{10}$.

Exercise induced anaphylaxis includes the clinical symptoms: pruritus, urticaria, angioedema, respiratory distress, and syncope. In some cases anaphylaxis is associated with food only after exercise, usually within five hours of the exercise. The association with food is subdivided into two groups: one where the specific food eaten is not relevant, and the other where a specific food must be eaten to elicit IgE-mediated hypersensitivity.

The clinical syndrome of food-dependent exercise-induced anaphylaxis (FDEIA) is characterized by the onset of anaphylaxis during or soon after exercise preceded by the ingestion of the offending food ${ }^{11}$. The activities that precipitate symptoms include: running, ball sports, and walking $^{12}$. FDEIA may be allergen specific or non-allergen specific. Numerous foods (e.g. shrimp, shellfish, chicken, wheat, nuts, some fruits, and vegetables) have been reported as allergens associated with FDEIA $^{13}$. The most common specific food allergen that induces FDEIA is wheat and in particular, $\omega$-gliadin ${ }^{11}$. Major proteins of wheat flour, gliadins and glutenins, as well as proteins of the albumin/globulin fraction are involved in wheat associated food allergy. Gliadins are significant allergens and different types are involved in the IgE response ${ }^{14}$.

If a positive reaction after physical exercise occurs independent of food intake, EIA is a possible diagnosis; however, it should be distinguished from cholinergic urticaria. In the case presented here, the negative response to exercise provocation alone and the positive reaction with exercise provocation after food ingestion pointed to FDEIA as the appropriate diagnosis ${ }^{15}$.

Avoidance of the combination of the food allergen and exercise is the most effective treatment in specific cases of FDEIA. In non specific FDEIA, patients should be instructed to avoid exercise for one-to-six hours after eating $^{15}$.

This is the first reported case of wheat-dependent exercise-induced anaphylaxis in the Korean dermatology literature. This case illustrates the evaluation of an unusual case of wheat allergy in a Korean woman.

\section{REFERENCES}

1. Moneret-Vautrin DA, Kanny G, Guerin L, Flabbee J, Lemerdy P. The multifood allergy syndrome. Allerg Immunol (Paris) 2000;32:12-15.

2. Palosuo K. Update on wheat hypersensitivity. Curr Opin Allergy Clin Immunol 2003;3:205-209.

3. Jarvinen KM, Turpeinen M, Suomalainen $\mathrm{H}$. Concurrent cereal allergy in children with cow's milk allergy manifested 
with atopic dermatitis. Clin Exp Allergy 2003;33:1060-1066.

4. Sehgal VN, Rege VL. An interrogative study of 158 urticaria patients. Ann Allergy 1973;31:279-283.

5. Harris A, Twarog FJ, Geha RS. Chronic urticaria in childhood: natural course and etiology. Ann Allergy 1983;51: 161-165.

6. Kanny G, Chenuel B, Moneret-Vautrin DA. Chronic urticaria to wheat. Allergy 2001;56:356-357.

7. Bock SA, Sampson HA, Atkins FM, Zeiger RS, Lehrer S, Sachs $M$, et al. Double-blind, placebo-controlled food challenge (DBPCFC) as an office procedure: a manual. J Allergy Clin Immunol 1988;82:986-997.

8. Metcalfe DD. Food allergens. Clin Rev Allergy 1985;3: 331-349.

9. Anderson JA. The establishment of common language concerning adverse reactions to foods and food additives. J Allergy Clin Immunol 1986;78:140-144.

10. Metcalfe DD, Sampson HA, Simon RA. Food allergy: ad- verse reactions to foods and food additives. 2nd ed. Cambridge: Blackwell Science, 1997:211-219.

11. Du Toit G. Food-dependent exercise-induced anaphylaxis in childhood. Pediatr Allergy Immunol 2007;18:455-463.

12. Gall $H$, Steinert $M$, Peter RU. Exercise-induced anaphylaxis to wheat flour. Allergy 2000;55:1096-1097.

13. Romano A, Di Fonso M, Giuffreda F, Papa G, Artesani MC, Viola $M$, et al. Food-dependent exercise-induced anaphylaxis: clinical and laboratory findings in 54 subjects. Int Arch Allergy Immunol 2001;125:264-272.

14. Battais F, Mothes T, Moneret-Vautrin DA, Pineau F, Kanny $G$, Popineau $Y$, et al. Identification of IgE-binding epitopes on gliadins for patients with food allergy to wheat. Allergy 2005;60:815-821.

15. Chong SU, Worm M, Zuberbier T. Role of adverse reactions to food in urticaria and exercise-induced anaphylaxis. Int Arch Allergy Immunol 2002;129:19-26. 